\title{
The Critical Decision Vortex: Lessons From the Emergency Room
}

\author{
Jean-Francois Coget \\ California Polytechnic State University, San Luis Obispo, CA \\ Eugene Keller \\ French Hospital Medical Center, San Luis Obispo, CA
}

\begin{abstract}
The dominant model of decision making, rational decision making, is increasingly challenged by research on intuitive decision making and emotion. This article contributes to the debate by articulating a model of how rational decision making, intuitive decision making, and emotion influence each other: the critical decision vortex. The critical decision vortex emerges from a discussion between an emergency room (ER) doctor and a management scholar. The experience of the doctor diagnosing and treating patients in the ER provides the background for a reflection on decision making in critical conditions. One of the main findings of this collaborative effort is that to be effective, ER doctors, like managers, need to remain centered in the critical decision vortex; they need to attend equally to their analytical conclusions, the intuitive hunches that come from their experience, and remain open and attentive to their emotions.
\end{abstract}

\section{Keywords}

rational decision making, intuitive decision making, emotion, doctors 


\section{Introduction}

This article is the result of a collaboration between Jean-Francois Coget, $\mathrm{PhD}$, an assistant professor of management at Cal Poly, San Luis Obispo, and Gene Keller, MD, vice-president for medical affairs at French Hospital, in San Luis Obispo. Jean-Francois conducts research on the role that emotions play in intuitive decision making and rational decision making. Gene has 30 years of experience in emergency medicine, and directed, among other things, the emergency rooms (ER) at Cedars Sinai's medical center and at Children's Hospital in Los Angeles. Jean-Francois and Gene met randomly and discovered a shared interest for decision making in critical situations. Through a series of dialogues, they elaborated the critical decision vortex, a model of how rational decision making, intuitive decision making, and emotions interact when doctors make critical decisions in the ER (c.f. Figure 1). Gene represents the "experience" aspect of the "Reflection on experience" piece, whereas JeanFrancois represents the academic, who relates Gene's experience to management theory.

The main point of this article is to describe accurately how experts make critical decisions in turbulent environments, such as the ER, characterized by high stakes, high stress, rapidity, incomplete information, overwhelming data, and overlapping processes. Decision-making models typically seek to identify neat causal sequences among their variables of interest, such as thoughts, intuitions, emotions, decisions, or actions, which they describe as discreet phenomena (Chia, 1994). Yet such models are descriptively inaccurate (Lipshitz, Klein, Orasanu, \& Salas, 2001). From a phenomenological point of view, people experience reality in continuous, rather than in discreet terms (Bohm, 1980; Derrida, 1981). The subjective, moment-to-moment experience of a decision maker is a flow of thinking, intuiting, feeling, and acting, rather than discreet thoughts, intuitions, emotions, and actions (Chia, 1994; Coget, 2004). While after the fact, decision makers might retrospectively invent an artificial story that connects sequentially a thought to a decision to taken an action (Weick, 1995), in the moment, the flows of thinking, intuiting, feeling, and acting interact with each other in numerous feedback loops, at times reinforcing, competing, or impeding each other (Coget, 2004). In the environment of the ER, the flow of experience of the doctor as a decision maker can be characterized as turbulent, reminiscent of rapids. As this article will illustrate, effective ER doctors navigate the flow of critical decision making by continually shifting between the three processes of thinking, intuiting, and feeling, a metaprocess that we call the critical decision vortex, whereas less effective ER doctors tend to ignore one or more of these processes. The metaphor of a "vortex" attempts to reflect the relentless shifting that occurs among processes and the lack of apparent order in which the shifts happen. The critical decision vortex model answers the call from Dane and Pratt (2007) to extend the literature on intuitive decision making by exploring its interaction with the emotion and the rational decision-making processes.

Though this article focuses on ER doctors, we believe the critical decision vortex model can apply to managers, too. As Mintzberg (1975) classically remarked, the manager's job, far from being characterized as planning, organizing, coordinating, and controlling, is in fact staccato paced and demands rapid-fire action. As work becomes faster paced, more dynamic, and more unpredictable (Cascio, 2003; Eisenhardt, 2000), the ER can thus be considered as a laboratory of what tomorrow's work conditions will be (Klein, Ziegert, Knight, \& Xiao, 2006). Because ER doctors routinely have to make critical decisions, their expertise in doing so might prove useful to managers (Auerbach, 2002), especially those who have to make critical decisions in turbulent environments (Brown \& 
Eisenhardt, 1997; Khatri \& Ng, 2000), such as CEOs in the boardroom, COOs, operations managers, or financial traders. The critical decision-making expertise of ER doctors may also be relevant to any employee working in high-reliability organizations (Bigley \& Roberts, 2001) or in the event of a crisis (Mitroff, 2004).

\section{In the ER With Dr. Gene Keller}

To illustrate the critical decision vortex model, let us follow Gene for an hour in the ER. A glossary of common medical terms that will be used in this article can be found in appendix. It is midmorning, and Gene is attending to the regular flow of ER patients, about 150 per day. The triage nurse brings in an elderly woman, approximately in her 80s, who complains of abdominal pains. Gene sighs. This is the 19th elderly woman complaining of abdominal pain this morning, none of which turned out to be serious. The last one also complained she had to miss her daily round of golf. As Gene starts asking the usual diagnostic questions, the lady says: "I've tolerated this pain for a few weeks. Today, it became so acute that I had to come to the ER." This statement strikes a chord in Gene, and he warms up to the stoic old lady. This motivates him to focus and to prioritize her care as immediate rather than defer her for an outpatient evaluation. He mentally consults his diagnosis algorithm for abdominal pain and orders a variety of tests, including an abdominal ultrasound. He then continues his diagnostic dialogue, in search for a clue that might help him automatically detect a pattern that fits one of the cases contained in his vast clinical repertoire, that is, to engage in intuitive decision making. Meanwhile, the triage nurse bursts into the room: "Doctor, you've got to see the patient in Bed 2. He does not look good." Gene deputes another nurse to attend the lady and walks to Bed 2.

Patient 2, a man in his 50s, complains of an excruciating chest pain. This symptom fits the pattern of acute coronary syndrome, which can mean the patient is having a heart attack. Gene thus follows the algorithm for the diagnosis of heart attacks. He orders an EKG, a chest X-ray, blood tests that evaluate strain or damage to the cardiac muscle, and IV access. Gene then asks the patient to describe his symptoms in more details. Something about the quality of the patient's pain strikes Gene as slightly different from the typical symptoms of a heart attack. In addition to the typical radiating pain in the chest and throat, the patient's pain reaches his back. All the other elements of the patient's history-his smoking, his mother's and brother's heart attacks, and so on-fit the diagnosis of a heart attack. But the illuminating detail of back pain disturbs Gene's heart-attack algorithm. His intuition alerts him to the possibility that the patient may have a dissecting aneurysm. If indeed the patient suffers from a dissecting aneurysm and is directed to the Cath lab for treatment of a heart attack, he will probably die. However, if he is not treated for a heart attack within 90 min of the initial symptoms, he will suffer irreparable cardiac damage, and possibly die, in the process. As Gene ponders over this diagnosis, he hears an announcement over the Paramedic ER radio.

A trauma patient is on his way to the ER. The patient, a young male, has been in a motorcycle accident. He is unconscious and in shock, with a blood pressure of 80 , and has been immobilized with a back board, with his helmet taped on. The paramedics indicate that they are doing a "scoop and run": Due to the potential severity of the case, they are bringing the patient directly to the ER, 
with minimal in situ treatment and diagnosis. Major trauma represents only a fraction of the cases of an ER, 1\%, which means 1 or 2 cases per day on average. However, they take up an inordinate amount of resources and time and are accompanied by an extra dose of drama: A "circus" of paramedics, firefighters, and/or police is accompanying the victim. Gene's adrenaline shoots up, upon hearing the announcement. His trauma algorithm pops up in his mind to help him prepare for the situation: put the patient in the trauma room, have X-ray and respiratory therapy stand by, and have a supply of Type 0 negative blood available, in case a transfusion is needed. Gene will have to diagnose this trauma patient very quickly with minimal information.

At this point, Gene has three critical cases in hand, with four or five other patients waiting in line, who could all potentially have serious conditions. He feels sympathy for the stoic old lady, and desire to help her; frustration at the problematic and life-threatening diagnosis of the second patient with chest pain; and anxiety at the prospect of the "scoop and run" trauma. To keep going, Gene has to muster his courage and envision his ability to cope with all these cases simultaneously. He asks whether Patient 1's results are back. They're not. He asks whether she's comfortable and focuses back on the second patient. Patient 2's chest X-ray is back and yields no additional information to decide the case. His medical history does not yield additional clues either.

The triage nurse interrupts Gene again to tell him that a mother, with Medi-Cal insurance, is waiting with her 2-year old baby. The baby has a fever of $105 \mathrm{~F}$ degrees, a symptom for which the worstcase scenario could be meningitis. The mother is banging on doors, demanding that a doctor see her baby immediately. Gene calls the hospital's cardiologist, a friend, and asks him whether he can come down to the ER to look at Patient 2. As Gene enters Room 3 to see the baby, the mother barks, "Am I waiting this long and being treated that way because I have Medi-Cal?" Gene replies, "I didn't know your insurance status." She then asks him, "Is it because I'm Black, then?" Gene now attempts humor: "Really, you're Black?" At this point, the trauma case arrives in the ER. Gene tells the mother he has to see the trauma patient: “I don't care about the trauma patient. Treat my baby!" Gene's already high stress level is exacerbated by the mother's attitude. He chooses to acknowledge the mother's anger, while simultaneously expressing his. He raises his voice: "You're right, I'll treat your baby immediately, and get the nurses to give him something for the fever, but I also have to treat a major trauma patient!" At this point, Gene takes her hand. "I promise: I will be back within 15 minutes. Look at your watch. I'll be back."

Gene enters the trauma room. For a moment, he is overwhelmed. He knows that he will have to spend an inordinate amount of energy and time to tackle this case, and yet, he has four other critical cases "cooking." Gene looks at his team of experienced staff and regains courage. As they start asking him the usual questions, such as "Which type of IV do you want hung?" their energetic presence propel him forward. At the same time, given the time pressure, Gene feels annoyed that the paramedics did not even cut off the patient's clothes. However, this is not the time to get angry at them. Every second counts. He thus enlists their help: "Cut the patient's clothes!" He orders an additional large-bore catheter IV to be started, blood drawn, and, in the absence of much diagnostic information, follows his trauma algorithm. He checks that the patient is breathing properly and readies for an intubation to be performed. He examines the chest and listens for lung damage. He examines the pelvic area and notices blood on the tip of the patient's penis. This indicates a 
probable pelvis fracture. He also notices that the patient's leg is positioned at an awkward angle. The nurses tell Gene that the patient does not have any visible deformities of the leg: They checked. He thus concludes that the patient may suffer from a fracture or dislocation of the hip. He carefully removes the patient's helmet after checking an X-ray of the patients neck on the backboard, taking care not aggravate underlying neck or facial trauma, and orders further X-rays and a CT-scan to be performed.

Emerging from the trauma room, Gene asks whether the cardiologist has returned his call. He hasn't; so he calls him back and asks whether he can come down: "I'm on my way." Gene wipes a tear from the corner of his eye: "Thank you." He then goes back to Room 3. He knows he will have to face the mother's anger. Some doctors choose to ignore such things, but Gene does not want it to loom like an elephant in the room and interfere with his work. He thus chooses one more time to acknowledge the mother's anger, to start defusing it, and then to enlist her help: "I know you're angry, but I really need your help to find out what's going on with your baby. I also need you to hold him, to keep him calm while I look at him." As Gene examines the baby, he notices obvious symptoms of an ear infection. He sighs in relief: "I've got good news! It's probably only an ear infection." Gene checks the baby's neck for rigidity and quickly does a complete exam. He orders antibiotics administered and asks the mother to stick around for another $30 \mathrm{~min}$, to make sure that the antibiotics are having the expected effect. The cardiologist is now with Patient 2, examining him, and decides that he is just suffering from a classical heart attack. He takes him off to the Cath lab. While Gene is waiting for the trauma's test results, he gets results from Patient 1's tests. The ultrasound of her abdomen indicates that she has gallstones. He now decides to take a moment for himself. He goes to the patient's room, takes her hand, and holds it for 2 minutes. He allows himself to feel his sympathy for a courageous patient. Providing her with emotional support allows him to feel good about himself and reset his negative emotions, so that he can recenter himself and continue to cope with the relentless pace of the ER. More patients are waiting, and Gene gets back in the ER. This example illustrates several important aspects of critical decision making in the ER:

1. The main task of an ER doctor is to rapidly diagnose patients and treat them. In theory, it occurs in two parts: Diagnosis is supposed to happen first and be followed by treatment. In practice, however, the two intersect in multiple feedback loops, with treatment often preceding a full diagnosis.

2. While diagnosing and treating patients, ER doctors need to constantly monitor and manage their resources and prioritize their actions to (a) determine which resources maximize diagnosis and treatment for each patient, (b) minimize demands on the hospital system, (c) prioritize needs across different patients, and (d) monitor their own capacity limitations (emotion, memory, etc.) to remain effective in the ER.

3. Each case can be considered as a series of critical decisions. To successfully diagnose and treat patients, doctors must remain centered in what we call the critical decision vortex. Diagnosis consists in narrowing down increasing amounts of information about a case to a pattern that can be acted upon, which happens thanks to three integrated processes: (a) rational decision making, often in the form of algorithms; (b) intuitive decision making, the automatic recognition of anomalies or patterns through experience; and (c) emotions. These three functions represent the three poles of 
the critical decision vortex, which check and balance each other. Neglecting one pole of the critical decision vortex can cause ER doctors to make poor decisions such as misdiagnosing patients, or "spinning around." In the next section, we discuss the relevant management literature on decision making.

\section{Reason, Intuition, and Emotion in Management Theory}

The bulk of research on decision making has focused on rational decision making. The process of rational decision making is typically described as (a) defining a problem, (b) identifying relevant criteria dimensions of the problem, (c) weighing the different criteria in terms of importance, (d) generating alternative solutions that address the problem, (e) rating each alternative on the relevant criteria, and (f) choosing the optimal solution (Bazerman, 1998; Kahneman, Slovic, \& Tversky, 1987; Simon, 1968). In medicine, rational decision making often takes the form of wellknown algorithms, which are taught in medical school and are reinforced throughout the residency period. Doctors are first taught to classify cases into categories of symptoms, such as "chest pain," "abdominal pain," or "trauma." They then refine their diagnosis within each of these categories by asking specific questions and performing specific tests to eliminate certain hypotheses and narrow down the possible causes to one primary alternative that they can act upon. The logic of the algorithms is rooted in medical science-statistics and probabilities about different medical conditions and their treatment, published in medical journals-and tradition-the cumulative experience of professors of medicine (Groopman, 2007). Technology that complements doctors' senses, such as X-ray machines and CT scanners, or knowledge, such as WebMD or even Google (Tang \& Ng, 2006), support doctors' rational decision-making process. Doctors' professional network of colleagues and specialists can also support their rational decision making by filling in knowledge gaps or providing second opinions.

An alternative model to rational decision making, intuitive decision making, has recently captured the attention of management scholars because managers report that they use it more often than rational decision making (Andersen, 2000), increasingly so, as they climb the professional ladder (Sadler-Smith \& Shefy, 2004), and because it is faster and more effective under certain conditions than rational decision making (Dane \& Pratt, 2007; Simon, 1987). Intuitive decision making is characterized as a rapid, nonconscious process that produces affectively charged judgments through holistic associations (Dane \& Pratt, 2007). Upon starting to practice medicine in the field, interns quickly realize that more experienced doctors reach quick diagnoses and provide expert care without debating rationally (Groopman, 2007). As they gain more experience, ER doctors increasingly rely on intuitive decision making. Klein (1993) has vividly illustrated intuitive decision making in his work with firefighters and soldiers. When making decisions in the field they often do not generate multiple alternatives and then choose one among them. Rather, skilled firefighters only generate one feasible course of action and enact it. In intuitive decision making, the cognitive process of rational analysis and choice is replaced by sizing up a situation and matching it with a prototypical situation that evokes a given course of action. Research on expert decision making has clearly established that repeated exposure to specific types of problems through practice and training is related to the ability to excel in a domain of activity (Ericsson \& Charness, 1994). Further studies of intuitive decision making show that experts often build accounts of the events that could 
have led to the current situation, which allows them to better size it up (Kaempf, Klein, Thordsen, \& Wolf, 1996). Experts also use stories to mentally simulate a course of action in the future and evaluate what will work and what might pose problems (Lipshitz et al., 2001).

Traditionally, emotions were considered to bias rational decision making (e.g., Janis \& Mann, 1977). It was, therefore, advised to ignore or control them, which is still the advice often given to medical students (Lerner, 2008; Morse, Edwardsen, \& Gordon, 2008). Recent research on emotional intelligence, however, has started to challenge such wisdom (Goleman, 1995; Salovey \& Mayer, 1990). There is now a growing body of research evidencing the positive role that emotion can play in rational decision making (for extensive reviews, see Forgas, 1995; Loewenstein \& Lerner, 2003) and intuitive decision making (Burke \& Miller, 1999; Hayashi, 2001; Sadler-Smith \& Shefy, 2004). Damasio (1998), for instance, has provided neurobiological evidence that people cannot make decisions when the regions of their brain associated with the emotion process have been damaged. He hypothesizes that critical events leading to strong emotions create somatic markers in a person's memory. When faced with similar events, the somatic markers elicit the same emotion in the person, which helps them make decisions. The somatic marker hypothesis is consistent with psychological research on emotion and memory, which suggests the existence of affective associative networks: Individuals experiencing a particular emotion are more likely to attend to emotion-congruent stimuli and retrieve memories and action scripts associated with that emotion (Bower, 1981; Parrott \& Spackman, 2000). A large number of studies have also found that positive affect facilitates the use of intuitive decision making, whereas negative affect, with the exception of anger, impedes its use in favor of rational decision making (Forgas, 1998; Isen, 2000; Lerner \& Tiedens, 2006).

Research on managerial decision making has underlined the importance of rational decision making, intuitive decision making, and emotion, the three poles of the critical decision vortex. However, how the three poles interact is still unclear. Although some research has investigated how emotion influences rational decision making, little research has investigated how it influences intuitive decision making, or how intuitive decision making and rational decision making interact (Dane \& Pratt, 2007). In which circumstances do rational decision making, intuitive decision making, and emotion supplement, complement, or impede each other?

We propose to investigate these questions by observing different configurations of the critical decision vortex as Gene faces different situations in the ER.

\section{Different Configurations of the Critical Decision Vortex in the ER}

Rational decision making is the default pole of the critical decision vortex that ER doctors usually start with. At the beginning of a diagnosis, when receiving information from the triage nurse, paramedics, or other ER personnel, doctors classify the case based on the key symptom(s) and then follow an algorithm designed to figure out the possible causes of the symptom(s). The trauma case described in our first example illustrates this configuration of the critical decision vortex: In the absence of much diagnostic information, Gene duly followed his trauma algorithm, aided by his team. Rational decision making is also the pole of the critical decision vortex that rookie doctors 
have to rely on at first, because they do not have enough experience to rely on intuitive decision making (Groopman, 2007). Gene remembers a case he had to treat during his first few months of residency in the ER. The patient was a physician in his 60s who complained of severe symptoms of indigestion after eating fish eggs. The patient remembered that certain foods had caused similar symptoms in the past. Gene followed the algorithm he had learned in medical school for the diagnosis of indigestion. Aside from gastrointestinal ailments, indigestion can be symptomatic of acute coronary syndrome, especially for men in that age range. Gene thus ordered an EKG performed, to evaluate the patient's heart condition, and ordered pantoprazole administered, to treat the symptoms of indigestion. The patient's symptoms disappeared with the administration of pantoprazole, and the patient himself indicated that his EKG results looked similar to his previous EKGs. Gene narrowed down his primary diagnosis to indigestion, and scheduled an in-depth gastrointestinal exam for the next day. However, the patient succumbed from a massive heart attack during his gastrointestinal exam the next day. Gene's rational decision making was not sufficient to alert him that the acute coronary syndrome hypothesis was the correct one.

As ER doctors garner more and more experience, they increasingly rely on intuitive decision making. All of the cases they treat get stored in their memory in more vivid detail than abstract knowledge, with their associated symptoms. Upon noticing subtle patterns, such as the color of skin, activity level, angle of limbs, smells, sounds of different organs, and subjective descriptions of pain, ER doctors are able to immediately diagnose an ailment without conscious need to reason. For example, a patient was once brought to one of Gene's interns with pneumonia symptoms. As the intern described his diagnosis to Gene the latter had a gut feeling and asked the intern, "Does the patient have a parrot?" The intern looked at Gene aghast: "What does a parrot have to do with the diagnosis of pneumonia?" Gene repeated, "Have you asked the patient if he has a parrot?" "No." "Let's go see the patient." Gene asked the patient, "Do you have a parrot?" The patient replied, "As a matter of fact, yes, and he has been sick..." The intern was astounded. Gene had just happened to come across a few cases of pneumonia caused by bacteria that often target parrots and can pass on to humans. He recognized subtle cues in the case that prompted him to check whether the patient had a parrot.

Rational decision making and intuitive decision making can interact in different ways. As seen in the previous example, or in the example of Gene hesitating about his patient with chest pain because of the quality of the patient's pain, intuitive decision making can support rational decision making by detecting anomalies that technology and rational analysis fail to detect (Klein, 1998). Intuitive decision making can thus redirect a diagnosis away from the wrong algorithm, preventing errors and saving lives.

Intuitive decision making can also outperform rational decision making in complex, yet urgent situations (Dane \& Pratt, 2007; Ericsson \& Charness, 1994; Simon, 1987). In some cases, Gene just takes a look at a patient and gets the correct hunch, such as, "This is a urinary tract infection." The hunch is then confirmed by further analysis $80 \%$ to $90 \%$ of the time. Acting on intuitive decision making to treat patients can be essential, given the limited time that ER doctors have to treat patients and the limited resources of the ER. Gene recalls a case in which one of the ER doctors working for him could not save a patient because he was waiting for a CT scan result and the CT 
scan was tied up with other critical patients. The doctor was following a rational decision-making algorithm, but Gene faulted the doctor for failing to start to provide care based on intuitive decision making. According to Gene, a good ER doctor starts providing care right away while starting to diagnose a patient and constantly updates and revises his or her diagnoses and treatments as time passes and different diagnostic and treatment paths are explored. Technology can not only assist rational decision making but can also create a dependency that prevents doctors from using intuitive decision making because the logical process that it follows is external to them. Although experienced ER doctors sometimes listen to their hunches against what technology tells them, Gene worries that younger generations of doctors increasingly lose their ability to do so, as they are increasingly socialized to rely on technology and ignore their senses, as illustrated with the example of the doctor waiting for the CT scan.

In addition to detecting anomalies or outperforming rational decision making in complex and urgent situations, intuitive decision making is also useful in synthesizing overwhelming amounts of information (Dane \& Pratt, 2007; Khatri \& Ng, 2000). As technology increases the level of details available, ER doctors are faced with information overload. Though rational decision making cannot cope rapidly with information overload, intuitive decision making allows expert doctors to rapidly do so.

Rational decision making can assist intuitive decision making in several ways as well. First, it can confirm intuitive decision making. This is why doctors order tests to confirm their initial diagnoses. Rational decision making can also outperform intuitive decision making where the latter fails. Occasionally, an initial diagnosis stops making sense, forcing doctors to find an algorithm that will help them progress in their inquiry. They can consult the literature and their colleagues, order tests, and reflect on the case. Most of the time, for an experienced and effective ER doctor, rational decision making and intuitive decision making complement and reinforce each other. What about emotion? What happens when we insert it in the equation?

Traditionally, emotions have been considered detrimental to decision making (e.g., Janis \& Mann, 1977). This view is justified in two ways. First, emotions can be understood to be primitive forms of intuitive decision making, attached to ancient action scripts that in many cases have lost their relevance in a modern world that has different constraints, threats, and opportunities (Darwin, 1894). For this reason, they can bias judgment by motivating an inappropriate behavior. Gene illustrates this possibility with the emotions of anger or resentment. The ER sees many difficult patients such as intoxicated individuals, drug addicts, felons, homeless people, or people driven by fear. These patients can be uncooperative and violent, as seen in the example of the distraught mother with a sick baby. Such patients can cause anger in ER doctors. Although Gene has become inured to abuse, having been insulted, scratched, punched, and even threatened with a gun several times, he really gets angry at patients who abuse the nurses. Gene has noticed that anger can cause him to deprioritize patients. Though such a reaction is understandable, it violates the ethical vow of doctors to treat all patients with an equally amount of care. Second, emotions, especially when they have a high intensity, have an irresistible quality: They interrupt other cognitive processes, including decision making (Frijda, 1986). High-intensity emotions can thus blur decision making, whether it be intuitive decision making or rational decision making. Gene recalls an incident in 
which he had to treat an advanced-stage leukemia patient whose neck tissues were filling with blood, which was gradually obstructing his respiration. The patient was male, Gene's age, and very similar to him in other ways, which led Gene to identify with him. He was overcome by empathy and fear. The procedure to save the patient from suffocation was pretty simple, and part of the basicABC of ER medicine: Gene needed to find an airway and pierce a hole through the neck to insert a breathing tube.Although the maneuver was made more difficult by the obscuring presence of blood in the tissue, Gene had performed this maneuver a countless number of times and become a recognized expert at it. Nonetheless, his overwhelming feelings blurred his judgment, paralyzed him temporarily, and complicated his finding an airway, which may have compromised care. The patient ultimately could not be saved.

Although emotions can impede decision making, they can also enhance it in five ways: (1) Emotions can inform judgment by initiating intuitive decision making or providing diagnostic information for rational decision making. Gene gives the example of disgust and anger. Upon entering a room, Gene was overcome by disgust at a foul odor coming from a patient. The patient, a middle-aged woman, was complaining of vague symptoms. Gene attended to his feeling of disgust and focused his attention to the woman's head. She was wearing a hat. "Do you have any problem with your head?" "No." "Can you remove your hat?" She did, and her hair appeared normal. As Gene started to examine her, he was again overcome with the feeling of disgust and the foul odor, and examined her hair, which he would not have normally done, given that ER doctors spend an average of 3 min with each patient. Behind a large clump of hair, the patient had an enormous skin tumor on the scalp, which produced the foul odor of decaying flesh. She was in complete denial of the symptom, refused to mention it, and was in fact trying to cover it up. When Gene mentioned the tumor to her, she explained that she must have been chemically burned by hair dye during her last visit to the hairdresser. Gene sent the patient to a cosmetic surgeon, where she had to have a large portion of her scalp removed. In another example, Gene was attending to a young patient, who was suffering from a bad open fracture of the leg and was unconscious, following an ATV (All Terrain Vehicle) accident at night. Upon entering the room, Gene felt a mounting anger. He stopped to analyze the origin of his anger and realized that he was angry at the recklessness of the patient. This prompted him to check whether the patient was intoxicated. The blood results confirmed that he was. He thus altered his trauma routine to take into account this condition. Gene's anger had triggered his intuition that the patient was intoxicated. (2) Emotions can assist decision making in the ER by energizing action. This is illustrated by the example of the old lady with gallstones. Gene's sympathy for her prevented him from putting her on the backburner during a difficult hour. Although Gene often feels an extra dose of sympathy for stoic patients, he feels sympathy toward all of his patients. Sympathy motivates him to keep working on their case even when facing a series of urgent cases. It heightens his memory, cognitive processes, capacity for multitasking, resistance to stress, resilience, and hope. Emotions such as sympathy, love, anger can all energize action, which is a key asset for ER doctors. (3) The particular emotion of empathy is crucial for ER doctors in at least three ways: (a) Empathy helps doctors to relax patients, which facilitates the administration of care and leads patient to communicate their symptoms more accurately which helps to diagnose them better; (b) Doctors who are judged to be empathetic to patients have a much lower incidence of malpractice lawsuits, regardless of their actual number and gravity of mistakes, because they make patients feel listened to and cared for (Ambady, LaPlante, Nguyen, \& Rosenthal, 2002; Levinson, 
Roter, Mullooly, Dull, \& Frankel, 1997); and (c) Empathy in itself is a form of care that is useful to give patients, although it is often overlooked by the medical community (Maguire, 1999; Morse et al., 2008; Taylor, 1988). Death, for instance, is considered a failure by many doctors. When doctors see death as inevitable, they thus have a tendency to exit the situation rapidly. Gene's empathy always motivated him to ensure that dying patients were comfortable and not suffering unnecessarily and took care to comfort their family. From a holistic and humanistic perspective, it is important for both the doctor and the patients to have a human rather than just a technical interaction. (4) Emotions help doctors recognize their limits and manage themselves so that they don't "spin around" or overtax themselves to the point of making mistakes. (5) Finally, emotions influence doctors and nurses' implicit moral judgment when they attribute the limited resources of the hospital and prioritize cases. As illustrated in the first example, a baby, as opposed to an elderly patient for instance, attracts an extra level of attention by the ER personnel and often receives priority. This finding was originally formulated by Glaser and Strauss (1964), who observed that nurses place an implicit social value on dying patients. Although ER doctors' ethics commands them to avoid preferential treatment, they are nonetheless routinely faced with dilemmas where they have to assign priorities to different cases. Although they base those decisions on several factors, such as severity, urgency, and treatability of cases, they also rely on emotions as cues that greatly influence the implicit social value they assign to patients.

\section{Discussion and Conclusion}

Based on Gene's experience and Jean-Francois's knowledge of the decision making and emotion literatures, we have a model of how rational decision making, intuitive decision making, and emotion interact. For an ER doctor, each case can be considered as a series of critical decisions that determine the progress of the diagnosis and treatment and the occurrence of critical mistakes. Critical decisions occur within what we call the critical decision vortex, which features three poles: rational decision making, intuitive decision making, and emotion. For doctors to make the right decisions, they need to remain centered within the critical decision vortex, allowing rational decision making, intuitive decision making, and emotion to inform, balance, and complement each other. When one of the poles is privileged at the exclusion of the other poles, the doctor risks committing a mistake or decreasing the quality and speed of his or her diagnosis and treatment. Though intuitive decision making and rational decision making can point in different directions, they can complement each other: intuitive decision making can alert rational decision making to revisit an earlier diagnosis or provide a fast diagnosis in urgent cases where the process of rational decision making would be too slow. Rational decision making can take over intuitive decision making where the later dead-ends and confirm or refine intuitive decision making. Though overwhelming emotions can interrupt both intuitive decision making and rational decision making, emotions of lower intensity provide valuable diagnosis information for rational decision making, can initiate intuitive decision making, energize action, facilitate empathy, help doctors recognize their own limits, and help them solve moral dilemmas.

Although this model is only based on the experience of one person, Dr. Keller, it yields a rich, organic understanding of how rational decision making, intuitive decision making, and emotion interact. Some intuition researchers have noted that most models of decision making are based on 
theory or on laboratory experiments using nonexpert college students making decisions in simplified contexts. Such contexts vary radically from the contexts in which experts often have to make decisions, which are characterized by "ill-structured problems, uncertain, dynamic environments, shifting, ill-defined, or competing goals, multiple event-feedback loops, time constraints, [and] high stakes" (Lipshitz et al., 2001, p. 334). We, therefore, join the intuition researchers' call for the naturalistic observation of experts making decision in their natural setting to build descriptively accurate models of decision making.

The critical decision vortex contributes to the literature on decision making by suggesting that the distinction between thought, intuition, emotion, and action is more blurry than often considered in the literature. The diagnosis arrived at by an ER doctor is the result of a series of overlapping and interacting bouts of rational decision making, intuitive decision making, emotion, and action. When Gene recalled different incidents in the ER, he often found it difficult to neatly separate the processes governing the three poles of the critical decision vortex, which contributed to our decision to use the word vortex. This observation is consistent with Dewey's (2002) psychological theory. Dewey considered that human behavior was the result of three interacting factors: intelligence, which approximates rational decision making; habit, which approximates intuitive decision making; and impulse, which approximates emotion. The field of organizational behavior might benefit from bringing Dewey's work back into contemporary theorizing, which has started to be done by Adler and Obstfeld (2007), who used it to extend current research on creativity. It would also be interesting to extend the critical decision vortex model by comparing and contrasting it with Dewey's theory.

We believe that the critical decision vortex model opens up avenues for further research. One possibility would be to explore the role that specific emotions play in the critical decision vortex. For example, in the case of ER doctors, we have seen that the emotion of empathy is crucial for helping them to elicit more and better quality diagnostic information from the patients and is an element of care in and of itself. We have also seen that the emotions of sympathy and anger energize action. However, anger can also bias doctors' judgment and affect the quality of the care they provide. Anger would, therefore, be an interesting emotion to study within the critical decision vortex context. Another interesting avenue would be to explore the role of emotion regulation in the critical decision vortex. Whereas it is useful to regulate some overwhelming emotions, it is also useful to attend to other emotions. What types of emotion regulation strategies work best to filter detrimental emotions out and allow helpful emotions in?

\section{Practical Implications}

Implications for managers can be derived from the critical decision vortex model. We will separate them into two categories. First, we will explore the individual, team, and organizational practices that could potentially enhance critical decision-making effectiveness. Second, we will explore the kind of traits and skills that may help individuals effectively navigate the critical decision vortex. 


\section{Practices That Could Potentially Enhance Critical Decision-Making Effectiveness}

First and foremost, the critical decision vortex model can help practitioners by demystifying decision making in turbulent environments and describing it more accurately than traditional decision-making models. Awareness of what the vortex feels like should allow decision makers to identify more clearly the different processes they experience in critical situations, and how they interrelate, and prevent them for experiencing guilt for not following strictly the traditional rational decision-making model. This should help them improve their critical decision-making effectiveness because expert performance has been shown to improve when practitioners receive accurate but gentle feedback (Ericsson \& Charness, 1994). The critical decision vortex model can also help practitioners recognize and avoid the most likely pitfalls of critical decision making: ignoring one or more of the poles of the vortex and "spinning around." Aside from this first practical implication, our survey of the management literature and of effective practices in the ER has yielded three practices that could potentially enhance critical decision-making effectiveness:

(a)apprenticeship,(b)regular peer-review sessions, and (c) reflecting on action.

The first practice that we believe might help improve critical decision-making skills is the organizational practice of apprenticeship. The model of apprenticeship was first developed during the Middle Ages. Young professionals aspiring to learn a specific craft would work under a guild master for about 7 years until they were themselves recognized as masters (Epstein, 1998). Following the guild tradition, the medical field still requires young doctors to go through a long period of residency training. During their residency, they receive daily feedback about their decisions from experienced doctors, which tremendously improves their critical decision-making ability (Groopman, 2007). Though business school students still occasionally intern in business organizations before they formally enter the workforce, they might benefit from a more structured apprenticeship system, like the one used in the medical field.

A second practice that may help improve critical decision-making skills is the organizational or team practice of regular peer-review sessions. Hospitals routinely conduct peer-review sessions during which they examine cases in which unsatisfactory decisions have been made. The goal of these sessions is not to assign blame or take disciplinary measures but rather to help the medical personnel develop their decision-making ability. Peer feedback sessions help ER doctors continue to analyze and improve their critical decision-making effectiveness beyond the residency period. Business organizations might benefit from such a practice. Though periodic performance evaluation sessions are routinely conducted in business organizations, these sessions are essentially tied to rewards and punishments; thus, they are likely to raise defensiveness in the participants and detract from learning (Argyris, 1991). It might, therefore, be effective to conduct routine peer feedback sessions aimed at improving performance that are separate from periodic performance evaluation sessions, as suggested by Culbert (2008).

Aligned with the first two practices, the management literature suggests a third, individual practice that may help practitioners improve their critical decision-making abilities: reflective practice inquiry (Schön, 1983). Reflective practice involves, among other things, journaling , questioning one's frames, and conducting personal experiments (for more details, see Schön, 1983). Despite 
being originally developed within the field of management, the concept of reflective practice has received more attention in fields such as nursing (Getliffe, 1996; Hahnemann, 1986) or education (McCrindle \& Christensen, 1995). The critical decision vortex model reemphasizes its importance in the business field.

\section{Traits and Skills Potentially Associated With Effective Critical Decision Making}

Beyond the aforementioned practices, it might be useful to identify traits and skills associated with effective critical decision making. This may prove useful in the selection of effective critical decision makers and the development of critical decision-making training programs. Four types of traits and skills may help individuals successfully navigate the critical decision vortex: those that (a) enhance intuitive decision-making effectiveness, (b) enhance rational decision-making effectiveness, (c) enhance the effective utilization and management of emotions, and (d) help individuals to balance the three poles of the vortex, keep attending to each of them, and prevents them from "spinning around." Based on these four categories, we have established the following tentative list of helpful skills and traits: high degree of situational awareness, capacity for mindfulness, high level of expertise, high IQ, high emotional intelligence, active listening skills, capacity for ego transcendence, strong action orientation, and a high degree of conscientiousness. We now go over each category of traits and skills in more details.

Situational awareness, the capacity to perceive environmental elements within a volume of time and space, to comprehend their meaning, and to project their status in the near future (Blandford \& William Wong, 2004; Endsley, 1995, 1997); mindfulness, the capacity to be aware of one's internal condition and external situation as fully and as consciously as possible (Jullien, 1996; Sun-tzu, 1988; Weick \& Putnam, 2006; Weick \& Sutcliffe, 2006); and expertise (Dane \& Pratt, 2007; Ericsson \& Charness, 1994), have all been shown to improve intuitive decision-making effectiveness. High IQ has been associated with a higher rational decision-making effectiveness (Frederick, 2005), whereas emotional intelligence, the capacity to perceive, understand, use, and manage emotions (Salovey \& Mayer, 1990) is, by definition, associated with the effective management of the emotional pole of the critical decision vortex and has been shown to enhance various types of work outcomes (Goleman, 1998; Goleman, Boyatzis, \& McKee, 2002; Huy, 1999). A strong action orientation (Diefendorff, Hall, Lord, \& Strean, 2000) and a high degree of conscientiousness (Kirkpatrick \& Locke, 1991; Marrick \& Mount, 1991) could help decisions makers avoid "spinning around." Finally, good active listening skills (Rogers \& Farson, 1979) and ego transcendence (Parameshwar, 2005; Peterson, Driver-Linn, \& DeYoung, 2002; Peterson et al., 2003) may help them to incorporate the input of others and, therefore, attend to all of the poles of the vortex. The traits, skills, and practices that we have identified as possibly enhancing critical decision-making effectiveness are of course tentative. Further studies are needed to investigate their validity.

In this article, we hope to have contributed to the decision-making literature by providing a model that starts to answer the call of intuitive decision-making scholars to integrate intuitive, rational, and emotional processes (Dane \& Pratt, 2007). The model suggests a number of practical implications that can potentially help managers be more effective when making critical decisions. We hope that further research will extend, validate, and critique the model to further our understanding of critical decision making. 


\section{Appendix}

\section{Glossary of Key Medical Terms Used in this Article}

ABC of ER medicine: a mnemonic that stands for "Airway, Breathing, and Circulation."

Cath lab: an examination room equipped to support the catheterization procedure, where a catheter is inserted into a large artery, to diagnose and treat heart attacks.

CT-scan: computer assisted axial tomography: a medical imaging method that generates a threedimensional image of the inside of a patient.

Diagnosis algorithm: a sequence of instructions that doctors follow to make a diagnosis based on certain symptoms. The instructions may include a particular set of questions to ask patients, a set of medical tests to order, and a decision sequence based on the results of these tests.

Dissecting aneurysm: a localized widening of an artery in which the artery's wall rips longitudinally. EKG: electrocardiogram.

IV: an intravenous drip system used to administer fluids and medication quickly.

Intubation: a procedure in which tubes are inserted in the throat, and sometimes the lungs, to assist respiration.

Medi-Cal: a state-sponsored medical insurance to assist underprivileged children in California. Pantoprazole: a drug used for short-term treatment of erosion and ulceration of the esophagus. Spinning around: a term used in the ER to refer to moments when a doctor does not know which actions to prioritize any longer and looses precious time hesitating between them.

Trauma patient: refers to victims of accidents: car accident, motorcycle accident, high-fall accident, gunshot wounds, and so on.

Triage nurse: the nurse who makes a first assessment of incoming patients and prioritizes them. 


\section{References}

Adler, P. S., \& Obstfeld, D. (2007). The role of affect in creative projects and exploratory search. Industrial and Corporate Change, 16, 19-50.

Ambady, N., LaPlante, D., Nguyen, T., \& Rosenthal, R. (2002). Surgeons' tone of voice: A clue to malpractice history. Surgery, 132, 5-9.

Andersen, J. A. (2000). Intuition in managers: Are intuitive managers more effective? Journal of Managerial Psychology, 15, 46-63.

Argyris, C. (1991, May-June). Teaching smart people how to learn. Harvard Business Review, 4, 99109.

Auerbach, P. (2002). Management lessons from the E.R.: Prescriptions for success in your business. New York: Free Press.

Bazerman, M. H. (1998). Judgment in managerial decision making (5th ed.). New York: John Wiley.

Bigley, G. A., \& Roberts, K. H. (2001). The incident command system: High-reliability organizing for complex and volatile task environments. Academy of Management Journal, 44, 1281-1300.

Blandford, A., \& William Wong, B. L. (2004). Situation awareness in emergency medical dispatch. International Journal of Human-Computer Studies, 61, 421-452.

Bohm, D. (1980). Wholeness and the implicate order. London: Routledge \& Kegan Paul.

Bower, G. H. (1981). Mood and memory. American Psychologist, 36, 129-148.

Brown, S. L., \& Eisenhardt, K. M. (1997). The art of continuous change: Linking complexity theory and time-paced evolution in relentlessly shifting organizations. Administrative Science Quarterly, 42, 1-34.

Burke, L., \& Miller, M. (1999). Taking the mystery out of intuitive decision making. Academy of Management Executive, 13, 91-99.

Cascio, W. F. (2003). Changes in workers, work, and organizations. In W. C. Borman, D. R. Ilgen, \& R. J. Klimoski (Eds.), Handbook of psychology (Vol. 12, pp. 401-422). Hoboken, NJ: John Wiley.

Chia, R. (1994). The concept of decision: A deconstructive analysis. Journal of Management Studies, 31, 781-806.

Coget, J. F. (2004). Leadership in motion: An investigation into the psychological processes that drive behavior when leaders respond to "real-time" operational challenges. (Doctoral dissertation, University of California, Los Angeles, United States -California). Retrieved July 5, 2008, from Dissertations \& Theses: The Humanities and Social Sciences Collection database. (Publication No. AAT 3169137)

Culbert, S. A. (2008). Beyond bullsh* t: Straight-talk at work. Stanford: Stanford University Press.

Damasio, A. (1998). Descartes' error: Emotion, reason, and the human brain. New York: Bard/Avon Books.

Dane, E., \& Pratt, M. (2007). Exploring intuition and its role in managerial decision-making. Academy of Management Review, 32, 33-54.

Darwin, C. (1894). The expression of the emotions in man and animals. New York: D. Appleton.

Derrida, J. (1981). Positions. Chicago: Chicago University Press.

Dewey, J. (2002). Human nature and conduct. Amherst, MA: Prometheus. 
Diefendorff, J. M., Hall, R. J., Lord, R. G., \& Strean, M. L. (2000). Action-state orientation: Construct validity of a revised measure and its relationship to work-related variables. Journal of Applied Psychology, 85, 250-263.

Eisenhardt, K., M. (2000). Paradox, spirals, ambivalence: The new language of change and pluralism. Academy of Management Review, 25, 703.

Endsley, M. R. (1995). Toward a theory of situation awareness in dynamic systems. Human Factors, 37, 32-64.

Endsley, M. R. (1997). The role of situation awareness in naturalistic decision making. In C. E. Zsambok \& G. Klein (Eds.), Naturalistic decision making (pp. 269-284). Mahwah, NJ: LEA.

Epstein, S. R. (1998). Craft guilds, apprenticeship, and technological change in preindustrial Europe. Journal of Economic History, 58, 684-713.

Ericsson, K. A., \& Charness, N. (1994). Expert performance. American Psychologist, 49, 725-747.

Forgas, J. P. (1995). Mood and judgment: The affect infusion model (AIM). Psychological Bulletin, $117,39-66$.

Forgas, J. P. (1998). On being happy and mistaken: Mood effects on the fundamental attribution error. Journal of Personality and Social Psychology, 75, 318-331.

Frederick, S. (2005). Cognitive reflection and decision making. Journal of Economic Perspectives, $19,25-42$.

Frijda, N. H. (1986). The emotions. Cambridge: Cambridge University Press.

Getliffe, K. A. (1996). An examination of the use of reflective practice within the context of clinical supervision. Journal of Advanced Nursing, 27, 379-382.

Glaser, B. G., \& Strauss, A. L. (1964). The social loss of dying patients. American Journal of Nursing, 64, 119-121.

Goleman, D. (1995). Emotional intelligence. New York: Bantam Books.

Goleman, D. (1998). Working with emotional intelligence. New York: Bantum Book.

Goleman, D., Boyatzis, R. E., \& McKee, A. (2002). Primal leadership: Realizing the power of emotional intelligence. Boston, MA: Harvard Business School Press.

Groopman, J. (2007). How doctors think. Boston, MA: Houghton Mifflin Company.

Hahnemann, B. K. (1986). Journal writing: A key to promoting critical thinking in nursing students. Journal of Nursing Education, 25, 213-215.

Hayashi, A. (2001). When to trust your gut. Harvard Business Review 78, 59-65.

Huy, Q. N. (1999). Emotional capability, emotional intelligence, and radical change. Academy of Management Review, 24, 325-345.

Isen, A. M. (2000). Positive affect and decision making. In M. Lewis \& J. Haviland-Jones (Eds.), Handbook of emotions (2nd ed., pp. 417-435). New York: Guilford.

Janis, I. L., \& Mann, L. (1977). Decision making: A psychological analysis of conflict, choice, and commitment. New York: Free Press.

Jullien, F. (1996). Traité de l'efficacité [A treatise on efficacy]. Paris: Grasset.

Kaempf, G. F., Klein, G., Thordsen, M. L., \& Wolf, S. (1996). Decision making in complex commandand control environments. Human Factors, 38, 206-219.

Kahneman, D., Slovic, P., \& Tversky, A. (1987). Judgment under uncertainty: Heuristics and biases. Cambridge; New York: Cambridge University Press. 
Khatri, N., \& Ng, H. A. (2000). The role of intuition in strategic decision making. Human Relations, $53,57-86$.

Kirkpatrick, S. A., \& Locke, E. A. (1991). Leadership: Do traits matter? Academy of Management Executive, 5, 48-60.

Klein, G. (1993). A recognition-primed decisions (RPD) model of rapid decision making. In G. A. Klein, J. Orasanu, R. Calderwood, \& C. E. Zsambok (Eds.), Decision making in action: Models and methods (p. 480). Norwood, CT: Ablex.

Klein, G. (1998). Sources of power: How people make decisions. Cambridge, MA: MIT Press.

Klein, K. J., Ziegert, J. C., Knight, A. P., \& Xiao, Y. (2006). Dynamic delegation: Shared, hierarchical, and deindividualized leadership in extreme action teams. Administrative Science Quarterly, 51, 590-621.

Lerner, B. H. (2008, April 23). A doctor's dilemma: Stay stoic or display emotions? International Herald Tribune. Retrieved April 23, 2008, from http://www.nytimes.com/2008/04/23/health/23iht-22essa.12270843.html

Lerner, J. S., \& Tiedens, L. Z. (2006). Portrait of the angry decision maker: How appraisal tendencies shape anger's influence on cognition. Journal of Behavioral Decision Making, 19, 115-137.

Levinson, W., Roter, D. L., Mullooly, J. P., Dull, V. T., \& Frankel, R. M. (1997). Physician-patient communication: The relationship with malpractice claims among primary care physicians and surgeons. Journal of the American Medical Association, 277, 553-559.

Lipshitz, R., Klein, G., Orasanu, J., \& Salas, E. (2001). Focus article: Taking stock of naturalistic decision making. Journal of Behavioral Decision Making, 14, 331-352.

Loewenstein, G., \& Lerner, J. S. (2003). The role of affect in decision making. In R. Davidson, K. Scherer, \& H. Goldsmith (Eds.), Handbook of affective science (pp. 619-642). New York: Oxford University Press.

Maguire, P. (1999). Improving communication with cancer patients. European Journal of Cancer, 35, 2058-2065.

Marrick, M. R., \& Mount, M. K. (1991). The big five personality dimensions and job performance: A meta analysis. Personel Psychology, 44, 1-26.

McCrindle, A. R., \& Christensen, C. A. (1995). The impact of learning journals on metacognitive and cognitive processes and learning performance. Learning and Instruction, 5, 167-185.

Mintzberg, H. (1975). The manager's job: Folklore and fact. Harvard Business Review, 53, 49.

Mitroff, I. (2004). Crisis leadership: Planning for the unthinkable. New York: John Wiley.

Morse, D. S., Edwardsen, E. A., \& Gordon, H. S. (2008). Missed opportunities for interval empathy in lung cancer communication. Archives of Internal Medicine, 168, 1843-1852.

Parameshwar, S. (2005). Spiritual leadership through ego-transcendence: Exceptional responses to challenging circumstances. Leadership Quarterly, 16, 689-722.

Parrott, G. W., \& Spackman, M. P. (2000). Emotion and memory. In M. Lewis \& J. Haviland-Jones (Eds.), Handbook of emotions (2nd ed., pp. 476-490). New York: Guilford

Peterson, J. B., DeYoung, C. G., Driver-Linn, E., Seguin, J. R., Higgins, D. M., Arseneault, L., et al. (2003). Self-deception and failure to modulate responses despite accruing evidence of error. Journal of Research in Personality, 37, 205-223.

Peterson, J. B., Driver-Linn, E., \& DeYoung, C. G. (2002). Self-deception and impaired categorization of anomaly. Personality \& Individual Differences, 33, 327-340. 
Rogers, C. R., \& Farson, R. E. (1979). Active listening. In D. Kolb, I. Rubin, \& J. MacIntyre (Eds.), Organizational psychology. Upper Saddle River, NJ: Prentice Hall.

Sadler-Smith, E., \& Shefy, E. (2004). The intuitive executive: Understanding and applying "gut feel" in decision-making. Academy of Management Executive, 18, 76-91.

Salovey, P., \& Mayer, J. D. (1990). Emotional intelligence. Imagination, Cognition and Personality, 9, 185-211.

Schön, D. A. (1983). The reflective practitioner: How professionals think in action. London: Temple Smith.

Simon, H. A. (1968). Administrative behavior: A study of decision-making processes in administrative organization. New York: Macmillan.

Simon, H. A. (1987). Making management decisions: The role of intuition and emotion. Academy of Management Executive, 1, 57-64.

Sun-tzu. (1988). Sun Tzu on the art of war: The oldest military treatise in the world (L. Giles, Trans.). Singapore: Graham Brash.

Tang, H., \& Ng, J. H. K. (2006). Googling for a diagnosis-Use of Google as a diagnostic aid: Internet based study. British Medical Journal, 333, 1143.

Taylor, K. M. (1988). "Telling bad news": Physicians and the disclosure of undesirable information. Sociology of Health \& Illness, 10, 109-132.

Weick, K., \& Putnam, T. (2006). Organizing for mindfulness: Eastern wisdom and Western knowledge. Journal of Management Inquiry, 15, 275-287.

Weick, K. E. (1995). Sensemaking in organizations. Thousand Oaks, CA: Sage.

Weick, K. E., \& Sutcliffe, K. M. (2006). Mindfulness and the quality of organizational attention. Organization Science, 17, 514. 


\section{Figures}

Figure 1: The critical decision vortex

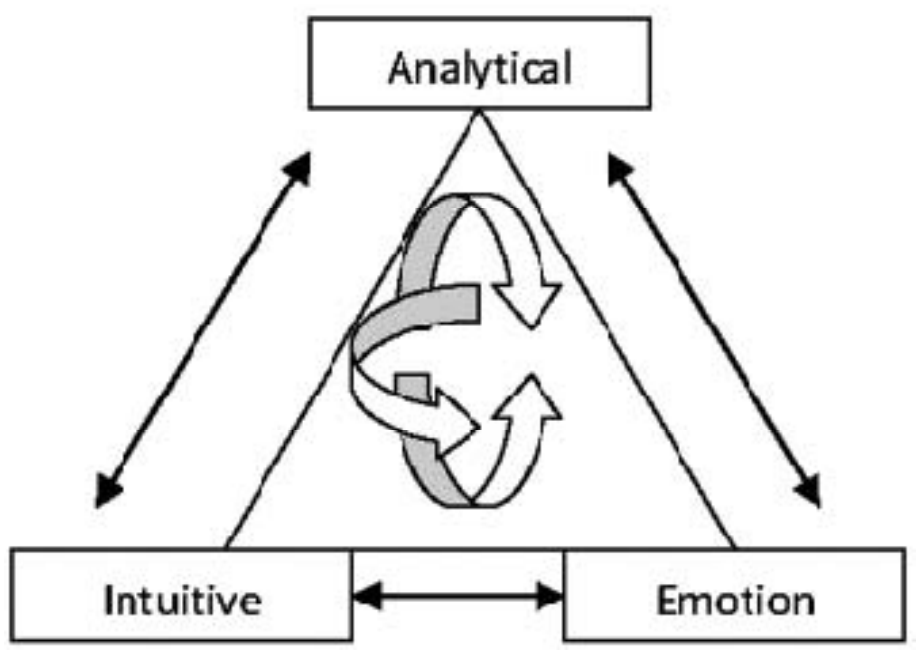




\section{Bios}

Jean-Francois Coget is an assistant professor of management at the Orfalea College of Business at CalPoly, San Luis Obispo, where he teaches organizational behavior and business consulting classes. He earned his PhD from the Anderson School at UCLA and was previously a faculty member at HEC Paris. His research interests include emotions in organizations, intuitive decision making, and charismatic leadership. His overarching professional goal is to contribute to the creation and the dissemination of actionable knowledge and practices that can help managers-citizens to organize a productive, creative, ethical, and sustainable cooperation among people.

Eugene Keller, MD, has been the vice president of medical affairs since 2005 at French Hospital Medical Center in San Luis Obispo, California. He graduated from Bowdoin College in Maine, then Tufts Medical School in Boston. After doing his internship and residency in Los Angeles he then spent 2 years in the Navy and then returned to Los Angeles where he was chief resident in pediatrics at Children Hospital (CHLA). He was then director of emergency services at CHLA. This was followed by a position on the faculty at UCLA as a staff emergency physician at Cedars Sinai Medical Center (CSMC). He served as director of the ED at CSMC until 1993 when he moved to central coastal California. Since that time he has been the director of the emergency departments at French Hospital Medical Center and Arroyo Grande Community Hospital. In 2003 he received his MBA from University of California, Irvine. Prior to his role as VPMA he spent almost 2 years as a senior medical consultant at hospitals all over the United States. 